\title{
Impact of Agriculture Radio Program among Rural \\ Farmers: A Case Study of Nuwakot District of Nepal
}

\author{
Shree Ram Khanal (PhD), Madhu Sudan Neupane (PhD)
}

Abstract

The study has explored the impact of agriculture radio programs among rural farmers to increase their productivity and quality of life in rural area. It represents the positive effects of radio program on farmers who use to listen agriculture radio program regularly. This qualitative study was carried out by basic observation, focus group discussion, and in-depth interview as data collection tools. The study revealed that agriculture radio program had changed the knowledge, attitudes and practise of the farmers to increase productions. Agriculture radio programs were associated with various factual and fruitful activities, such as planting hybrid rice, off-season vegetables, using modern technique of farming, goat farming, poultry farming etc through agriculture radio programs. Enough resources, technical knowhow and incentives are crucial for the enhancement of the standards of life of farmers as well as their productivity.

Key words: Rural radio, Agricultural radio program, agriculture based livelihood, rural community, modern farming

\section{Introduction}

Mass media has been considered as an agent of changing perceptions of the peoples that helps to transform their opinions, behaviors and work efficacy towards socialization. It has been crucial to mobilize the people of diverse ethnic groups, communities, religious groups, cultures and ideology through development activities. Media has to disseminate true information for creating social 
awareness to make active participation of people in development activities in various aspects. Radio is the cheapest and useful technology. It is easily accessible medium of communication technology in each and every corner of the country. Radio can play key role as the medium for National development (CEDA, 2001). The study has focused on positive impact of agriculture radio program in rural communities to uplift the livelihood of farmer by adopting modern ways of agriculture.

Media effect shows new horizon of agriculture concept, behavior and action of the people which has brought direct or indirect changes. According to Price (1998:28), the effect of media means the change in concept and behavior of the receivers, their socialization, and social control and so on. Mass media have cognitive, affective and behavioral effects. Projection of the content (message) of the radio indicates, affective impact and behavior effects are based on attitude and behavioral observation as well. They have positive and negative impressions.

Rural people can easily use radio for receiving agriculture information as their concerned. It is much cheap, light and portable. Radio is the most effective medium for disseminating intendent and untendent message for creating awareness and innovation in rural community to conduct rural communication (Joshi, 2000; UNESCO, 2003; Khanal, 2013). According to White (1994), Radio should be used to promote community development and innovation to increase community participation. There are difference in the level of awareness on country people who have not radio at their home. The people who have radio at their home has higher level of awareness with comparing remaining people who still are not able to buy radio for getting information as their concerned. So, radio imparts knowledge and brings changes in behavior of the people (Jamison and McAnany, 1970, p. 96).

FAO (2001) mentions that the people of developing countries can take advantage from radio transmission. Radio can play vital role to bring the changes among the behavior of the people for agriculture, health, education, local market and other contemporary issues. One of the study shows the impact of the radio contents in Britain, whereas The Archers, a soap opera has brought agricultural innovation among the British farmers. The study shows that the opera has given information about new techniques of farming, new methods of crops production, pest control and strategies, and prevention of animal diseases. Similarly, CEDA (2001) states that the agriculture program produced by Agriculture Information and Communication. Radio Nepal and Nepal 
Television have left positive impact on the audience. The study further claims that the audiences do not only have information and knowledge from the program transmitted by Radio Nepal and Nepal Television but also have brought the gained knowledge into practice to some extent.

It has revealed that agricultural program like J. T. A. and Grandma' on Friday, question answer on Monday, veterinary series' on Tuesday, discussion on Friday and agricultural miscellaneous on Sunday are popular among the audience. The study further has pointed out that the farmers have positive attitude toward agricultural program, for they can use the gained knowledge while farming the crops. However, they lack motivation because they do not have sufficient irrigation facility.

There are government, private or commercial and community radio ownership in Nepal. According to the ministry of Communication \& Information Technology, Government of Nepal distributed license to 1127 institutions for radio broadcasting, 800 radio stations are on air exited. Although, radio have been facing numbers problems and challenges, F.M radios are getting popularity day by day in rural areas. Nuwakot district has historical values. It has own importances for supply agriculture production to the capital city Kathmandu of Nepal. Geographically, the land of Nepal has divided into three regions, such as mountains region, hilly region and plain region. The 71 percent population is dependent on agriculture. The major agriculture activities include the production of cereals, cash crops, fruits, vegetables, pulse, fishery, livestock and poultry farming.

\section{Objective}

- To look out actual situation and effects of Radio program on farmers.

- To analyse the impression of agriculture information among target audience to increase productions.

\section{Methodology}

The Study has based on qualitative data. Observations, Focus Group Discussion and in-depth interviews were conducted for acquiring information and applied to make this research credible and valid. The study covers three rural municipality such as Panchakanya (Kabilash), Likhu (Dhukare), Tadhi (Bahunbesi) areas of Nuwakot district, Bagmati province. In the study, Panchakanya (Kabilash), Likhu (Dhukare), Tadhi (Bahunbesi) have selected as a sampling district to find out awareness level of the people, excessive agriculture activities for identifying pocket area of modern farming. The researcher has used observation sheet, focus group discussion and 
interview as an instrument and tools for data collection. This study was conducted for a period of 4 months from $3^{\text {rd }}$ July 2021 till 2nd October, 2021 in Nuwakot district of Nepal.

\section{Implementation tools and techniques for data collections}

During the time of study, the researchers were provided agriculture radio programs for 20 farmers (participants) of concerned areas. Then after, there way of farming were observed equally. Then after, the researchers were recorded the perceptions and experiences on radio program of the farmers. Informal conversation were done with local language. Correspondingly, five radio broadcasters and station managers were interviewed. Five radio stations such as Radio Nepal (First public radio of Nepal), Krisi radio (Nuwakot) F,M., Trishuli F.M. and Tadhi F.M agriculture programs were sampled for the research.

This study has applied participatory and non-participatory observation methods. The farmers were asked common queries about farming in front of the local farmers by the researchers. The observation was conducted about the influences of radio program being the time of planting the crops in the field, diseases found in the crops, using pesticides, using seeds and fertilizer, harvesting and marketing the products.

\section{Impacts factors:}

The study found that farmers use to listen radio while working in the field. They were listening news and folk songs more than the agriculture program. On the basis of observation, the radio stations lacked well managed newsroom and office and sufficient manpower to make the radio program effective and research oriented. There was less number of news-makers/ reporters because of the lack of motivation and enough salary and facilities due to the income and geographical areas. Some of the news rooms and reporters were totally depended on sources of information such as telephone inquiry, internet and online. Some of their news programs structures influenced by Kathmandu based radio stations, radio networks, CIN, BBC and so on.

Focused group discussions (FGD's) were conducted in different locations of Province -3, Nuwakot district.. The participants of the focused group discussions were encompassed from different professions, age groups and gender. The discussions included farmers, teachers, journalists, women and the representatives from the locality and the consumers of radio program 
from age 24 to 70s. Each focused group included 12 participants. The researcher played the role of moderator. FGD was conducted in local language. (How many FGD, mention as footnote).

\section{Theoretical framework:}

The diffusion of innovation theory has applied as theoretical framework for this study. Diffusion of innovation theory argues that the audiences receive innovations, knowledge and technology through the mass media like radio. This theory was developed before $20^{\text {th }}$ century and it was further improved by E.M. Rogers, assists to transform society as context of modernity. According to Mishra (2001), communication motives to adopt the innovation promptly. Communications should be able to enhance the living standard of the people about new ideas, and innovations across the world. Since radio is effective tool of rural communication, it diffuses new or innovative ideas pertaining agriculture. According to Rogers (2003:176), there are five stages in innovation process: Knowledge, Persuasion, decision, implementation and conformation. Rogers has claimed "In knowledge stage, an individual learns existence of innovation and seek the innovative information. Individual is motivated to understand more about innovation in awareness stage. Similarly, Individual forms positive or negative attitude towards innovation in persuasion stage. Acceptance or rejection remains in decision stage and individual brings the innovation into practice is implementation stage". Rayan \& Gorss (1943) found that diffusion of innovation plays important role to hybrid seed corn among farmers. This opened the door for wider discussion on diffusion approach.

The peasants were highly impressed and applied modern farming methods in their practice in full scale which was on air through radio.

\section{Data presentation and Discussion}

\section{Impact of Radio Program in Agricultural activities in practice in Nuwakot}

Farmers of villages have been highly influenced by listening radio program pertaining agriculture and they have changed their living standard in Nuwakot district. Govinda Dhungana, is a leading farmer of Dhekure-1, Likhu Municipality has known as the progressive farmer in the district. However, in the past, it was difficult for him to earn livelihood and support the children's education from the agricultural product as the family was big. He shared his experience in the way: 
"I listened usually listen agriculture program broadcasted from Radio Nepal. I was influenced by one of the success story of a farmer of Chitwan, and I also influenced from the radio interview with the successful farmer".

In the past, his income and life standard was average due to traditional farming system. Now, his income and life standard has been improved as he began modern farming three years ago. He gives its credit to agriculture program of Radio Nepal.

"I planted potato, cauliflower and cabbage in 5 Ropani (area) of land, and planted hybrid paddy in 10 Ropani. The modern vegetable farming increased my income and improved my livelihood. I started to send his children to private school".

When he has problems he asks to J.T.A (Junior Technical Assistant) and takes his suggestions. He frequently takes part in the trainings provided by District Agriculture Office. Dhungana regularly listens to the agriculture program of Radio Nepal and writes letters to the program times and again putting forward his queries. (Dhungana, 2021, a. Personal Communication)

Similarly, Shahadev (43), an active farmer of Tadhi rural municipality -5 ,Bahunbesi, expresses his viewpoints :

"I have been doing modern farming of potato in 6 Ropani of land, and planting hybrid paddy. From the farm production, he has been supporting his family of 4 members well".

He mentioned that he learnt about the use of seed, fertilizer and pesticide from agriculture program of radio. According to him, agriculture program is practical and highly useful to the farmers. (Adhikary, 2020, b. Personal Communication)

Gehendra, a leading farmer of Panchakanya Rural municipality ward no. 2, is the regular listener of agriculture program transmitted from Radio Nepal. He states that especially agriculture programs (broadcasted on Monday and Thursday) are more useful to the farmers. He has been doing modern farming for the last ten years. His past experiences as:

"Before this, it was difficult for him to earn his livelihood. It was very hard to support the family and the education of two daughters and three sons. His income increased and life standard changed as he chooses modern farming along with business. He planted modern 
grass (jai ghans), tress for fodder, coffee, hybrid rice, vegetables like potato, tomato in 17 ropani land, and planted sisau tree in 5 ropani. He shares his experience that he has already earned three lakh from sisau farming".

From this income, he has been supporting the college education of his five sons and daughters in Kathmandu. The middle-age farmer Rijal has biogas plant at his home. He has also made modern house in the village with his income. He says that it has been very easy for him to support his family. He advises other farmers in the village to follow modern techniques in farming and agriculture.( personal communication, Rijal, 2020).

\section{Expectation of farmers form the Radio}

Most of the participant farmers in focused group discussion revealed that they listened to the agriculture programs of Radio Nepal to get information about farming. In addition to this, it is also observed that they listened to radios of their neighboring district and some local F. M. radios to get information about agriculture.

The participants of focused group discussion (FGD) in Dhikure disclosed that they could not listen agricultural programs from local F. M. radios as such programs have not been transmitted regularly from these radios. As a result, they are compelled to listen Radio Nepal. The researcher also realized this truth as the radio set was tuned; standard agriculture programs were not found in local F. M. radios, but the programs of Radio Nepal could be listened well.

Agriculture programs seemed to have been more popular among the farmers of rural area because their livelihood of is dependent in agriculture. In this context, the study of Hariyana University (1985) in Hariyana can be relevant as it states that the senior farmers of rural area listened to agriculture programs more regularly than the listeners in the urban area.

One of the participants of FGD said that he has been listening to Radio Nepal as it provides useful information about livestock farming and agriculture.

He further added:

"There are not such programs in local radios. The local radios should attract the ordinary people by producing and transmitting effective programs". 
Kamala Thakuri (36 years) from preferred to listen Nuwakot FM as it is the radio of their own locality and it gives useful programs related to agriculture and livestock farming. It has been observed that after the establishment of local radios, the audiences of agriculture programs have been encouraged. Simalarly, Ramesh, (32 years), stated that he has been encouraged by the establishment of local radios and their agriculture programs.

"I like agriculture programs as they present the profile of young and successful farmers. So, I have been regularly listening to agriculture programs for 5 years".

The participants of FGD expressed that they have been more enthusiastic to listen programs afterward the establishment of local radios. Most of the participants in FGD pointed out that the language of agriculture programs transmitted from radio is a bit difficult. Shahadev , 43, suggested that the ordinary folks like him would understand the agriculture programs if the language used in the program were simple. However, he pointed out that the presenter of radio programs of local F.M. radios used simple language and presented programs in suitable manner. On the other hand, local F. M. radios have language errors, mistranslation and editorial weakness, he stated.

"There is lack of field based agriculture program in local radio. Sometimes, local radios forget their responsibility and neglect farmer's psychology and need".

Arjun (46) shared his experience that many farmers have planted hybrid rice, are doing poultry farming, potato farming, beekeeping and producing offseason vegetables using modern techniques of farming that they learned from radio programs. It has observed that some of the farmers have done farming as mentioned in the radio programs whereas other have not done so, for they said they did not have budget for that.

Janaka, 52, one of the participants, in interview agreed that she learned the technique of planting hybrid rice from radio programs. She said:

"When I planted traditional rice seed my conditional was poor. I had difficult to sustain my family. When I got knowledge about hybrid seed and modern farming, I planted hybrid rice and got more production that made my livelihood easier". 


\section{Level of the awareness of the Radio listenership of agriculture and its impact factor table: 1}

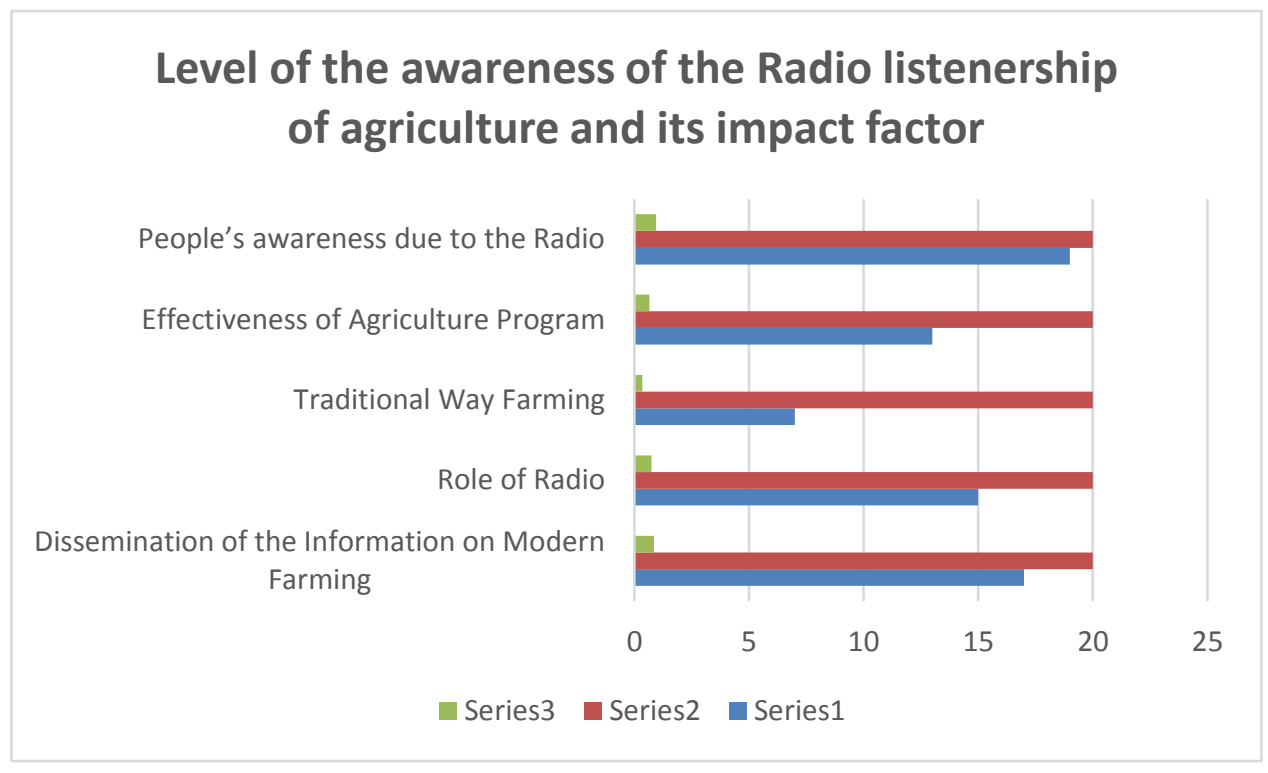

\section{Findings}

The major source of income of the people living in rural area is agriculture in Nepal, especially Nuwakot district. The farmers are doing livestock farming using modern techniques like cows, buffalos and goat keeping, poultry farming, bee keeping, and planting hybrid rice, potato, offseason vegetable, and producing milk and milk products. The farmers of this district can increase their income through livestock farming, cash crops and off-season vegetable farming in the fertile land. The present study reveals that radios are playing vital role to diffuse the concepts of modern farming in Nuwakot district. The farmers of this area are applying modern techniques of farming discarding the traditional ones. Agriculture program transmitted by Radio Nepal are popular mostly in rural areas of Nepal.

Radio program have positive impacts to change people's life style. The study reveals that the level of awareness of people, who have been listening radio, is higher than the people who have not done so. The study depicts that radio program helps farmers to disseminate the knowledge pertaining agriculture and its modernization. The agriculture radio programs have positive influences in famers and they been have engaged in various fruitful activities. There is few radios 
station who have given priority to the agenda of farmers although the economy of rural Nepal based on agriculture.

\section{Conclusions}

It has been realized that the medium of radio should be developed participatory communication approach. There are lack of research on the impact of radio program among farmers. So, Nepali government has to motivate and provide assistances to disseminate and design radio program. Radio stations of rural areas have to make effective radio program like Radio Nepal. On the other hand, it is necessary to be free from the influence of interest groups of local radios. Local radios (specially, community radio) should be reinforced by providing enough resources to broadcast agriculture programs to people.

\section{References}

Bhagat, R. (1985). Impact of radio on farm women. Maharastha, Journal of Extension Education, 4(1): pp53-58).

CEDA (2001). Impact Evaluation of AICC's publication, radio \& Television program. Report. Kathmandu: Centre for Economic and Development Administration.

David,M.J.\& Fleix,L. (1991). Radio's role in rural development: A case analysis of Mahawali community radio Srilanka. Losbunos: Philippines.

FAO (2001). FAO Final Report. Rome: Italy.

Gupta, V.S.(1999). Communication Technology. Media policy and National Development. New Delhi: Concept Company.

Jamison, D.T.,\& McAnany,E.G. ( 1970). Radio for education and development. London : Sage publication.

Joshi, U. (2001). Text book of mass communication. New Delhi: Anmol Publication.

Khanal,S.R. (2011). Role of radio on agricultural development: A Review. BODHI: An Interdisciplinary Journal, 5(1): (pp.16-20).

Khanal,S.R. (2013). Radio Prabhav [Radio Impact]. In D. Aryal, B.K.C,T, Pathak (Eds.). Media Reader. (pp. 217-223). Lalitpur: Jagadamba Prasashan.

Khanal, S.R. ( 2015). Effects of radio progrmmes in rural areas of Nepal: A study of Nuwakot District. Unpublished PhD Dissertation, Nepal: Tribhuvan University.

Kundra, S. (2005). Basic Audio-visual media. New Delhi: Anmol Publications. 
Mattelart, A.\& Mattelart, M.(1998). Theories of communication: An Introduction. London : Sage publication.

Mishra, P.R. (2001). Development communication. In Kharel, P.(ed). Media Practices in Nepal ( pp. 143-184), Kathmandu: Nepal Press institute.

Ministery of Information \& communication (1998). Broadcast Guidelines. Kathmandu: MOIC.

Price,S. (1998). Communication Studies. Singapore: Addison Wesley Longman Limited.

Rogers, E.M. ( 2003). Diffusion of innovation, (4 ${ }^{\text {th }}$ edition). New york : Free Press.

UNESCO(2003). Farm radio handbook. Paris.

White, R. (1994). Community radio as an alternative to traditional broadcasting. Media Development, 4(9): (pp. 120-126). 